\title{
Fabrication of transitional immediate complete denture
}

\author{
Mariana Yankova $^{1}$, Diana Fetfova ${ }^{2}$
}

1. Assistant Professor, Department of Prosthetic Dentistry, Faculty of Dental Medicine, Medical University - Sofia;

2. Fifth year student, Dental Medicine, Faculty of Dental Medicine, Medical University - Sofia;

\section{Abstract}

The case report presents a clinical case of completely edentulous patient, in which during the course of conventional prosthetic treatment, we fabricated a preliminary, transitional complete denture. It was made in two clinical appointments according to the functional, aesthetic and psycho-preventional requirements.

Keywords: immediate complete denture, transitional complete denture, intermediate complete denture

\section{Background}

In the cases of completely edentulous patients, sometimes the fabrication of preliminary complete dentures is mandatory. They could be conventional immediate dentures or interim immediate dentures also known in the literature as transitional denture construction (1). "Immediate denture" means an artificial teeth construction which is placed into the mouth immediately after the natural teeth extraction (2) or teeth that are due to be extracted for some other reasons. The construction may be a bridge, removable partial denture (3) or complete denture (4). The immediate denture should be planned as an overdenture (5), in the cases when the teeth extraction will not be done in one clinical appointment $(6,7)$. The immediate dentures are preliminary dentures and there are two types according to the used technology. The first impression of both of the types is taken before the teeth extraction. 
The conventional immediate denture is fabricated over the cast of the first impression. The extraction teeth should be trimmed off and their ridges are shaped in the appropriate way $(2,8,9)$. This kind of denture is placed immediately after the teeth extraction. At first we may make soft denture lining (10). Six months later it should be relined with heat curing acrylic resin. At this way the denture could turn into a permanent one. A new permanent denture should be done in two years (11).

In the cases of denture fabrication after the teeth extraction, it is defined as transitional or intermediate denture. It is used for a short period of time - three to six months and is followed by permanent denture fabrication in the classical technology. There are various technological approaches, described by different authors $(3,4,6,12,13,14)$.

In the cases of patients with old bridges, mounted on the extraction teeth, they may be used as a prototype during the fabrication of the teeth of the denture (4) or to be embedded in the denture $(12,13$, 14). Some authors offer temporary lining of the ready-to-use dentures with tissue conditioner or soft lining materials $(10,13,14)$.

\section{Case description}

G. D., female, 73 y.o. came to FDM, Sofia, in the practical lessons of Clinics of PDM with a removable maxillary partial denture replacing premolars and molars and metal-fused-to-porcelain bridge in the frontal area. The patient complained by instability of the prosthetic constructions and discomfort during eating and speaking function. In the clinical check-up we found out that all the abutment teeth have been extracted and the denture has been attached to the bridge with clasps (fig. 2), which was wide apart from the alveolar ridge due to the recent extraction of all teeth. The patient was already completely edentulous. The multiple extraction time that has passed was not enough for the alveolar ridge shaping with a view of fabricating definitive complete denture. The patient insists not to be left with the edentulous maxilla. We suggested her a transitional complete denture, which she would use during the healing period and before the definitive complete denture fabrication. The patient's old prosthetic constructions were suitable to be included in the transitional complete denture (fig. 1).

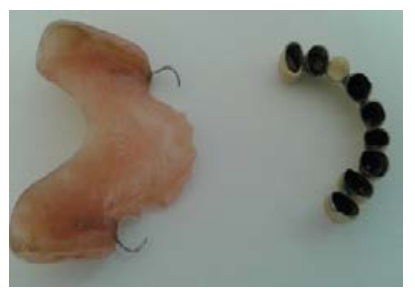

Fig. 1 Old denture constructions - separated 


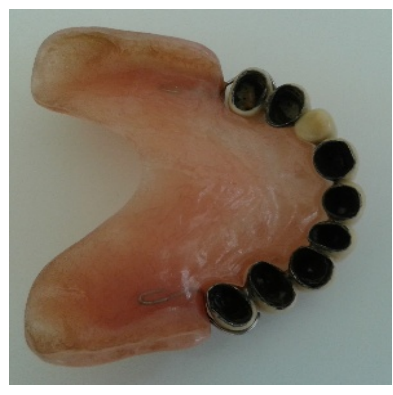

Fig. 2 Old denture constructions - connected by clasps of a partial plaque denture

In the same clinical visit we took a two-step impression using a putty-bodied (Elite HD, Zhermack) and light body material with low viscosity.

We used the putty material to shape the missing vestibular plaque of the future complete denture, and the low viscosity material to be more accurate with taking the impression of the denture area (fig. $3-a$, b; fig. $4-\mathrm{a}, \mathrm{b}, \mathrm{c}$ ). In order to maintain jaw relation, the impression has been taken by using Popov's method (8).

Fig. 3a

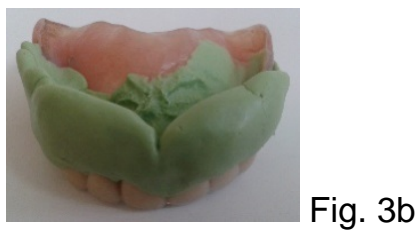

Fig.3 (a, b) An impression with putty impression material - axial and frontal view

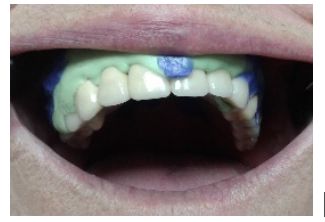

Fig. $4 a$

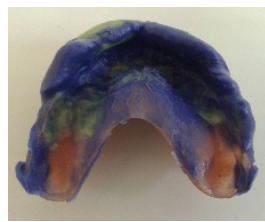

Fig. $4 \mathrm{~b}$

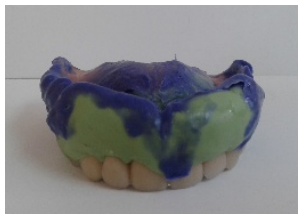

Fig. 4c

Fig. 4 Final impression - intraoral view (a), axial view (b) and frontal view (c)

A master cast has been fabricated (Fig. $5-a, b, c)$.

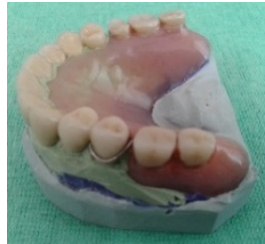

Fig. $5 a$

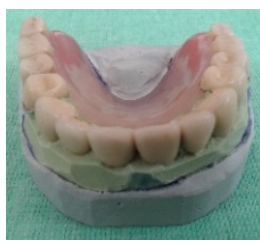

Fig. $5 b$

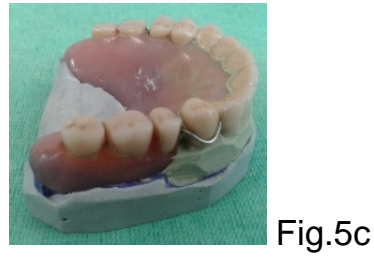

Fig. $5(a, b, c)-$ The moulded model 
Before the constructions and the master cast investing, we made an wax try-in to improve the transition between the MFTP bridge and the denture and to shape the ridges of the denture (Fig. $6-a, b, c$ ).

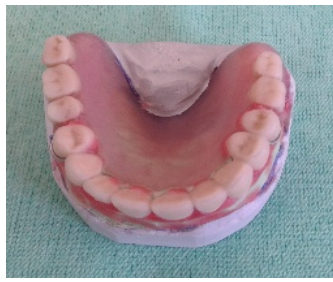

Fig. 6 a

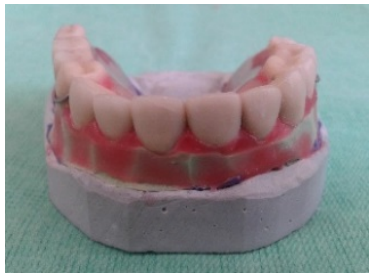

Fig. 6 b

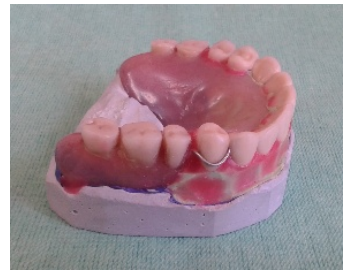

Fig. $6 \mathrm{c}$

Fig.6 (a, b, c) A wax try-in

The master cast and the waxed denture constructions were invested into a flask. The other stages have no difference with the stages of the classical technology of relining of complete dentures (Fig.7, fig. 8 -a, b, fig.9 - a, b).

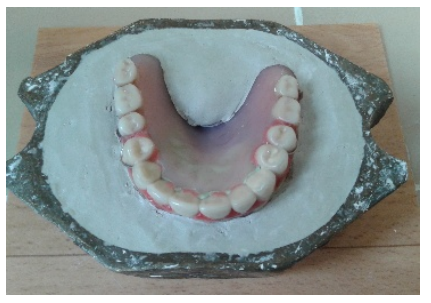

Fig. 7 Denture invested in a flask

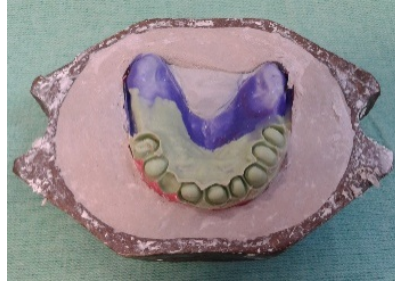

Fig. $8 a$

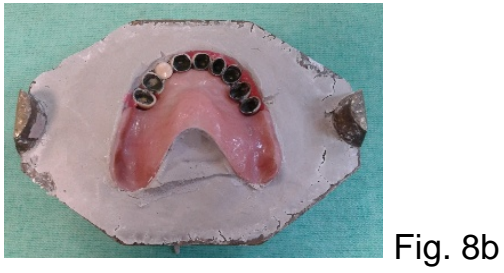

Fig. $8(a, b)$ - Opening of the flask before wax elimination and removal of the impression material

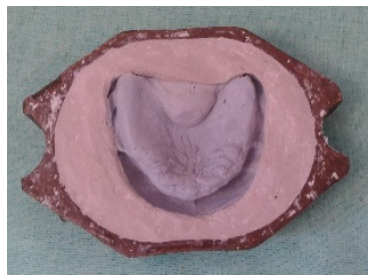

Fig. 9a

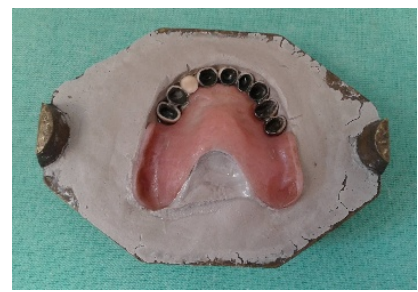

Fig. $9 b$

Fig. $9(a, b)-$ Opening of the flask after wax elimination 


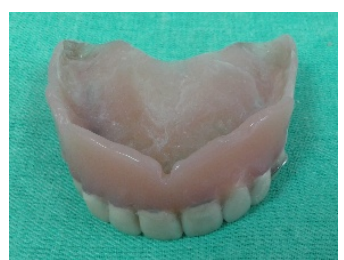

Fig. 10a

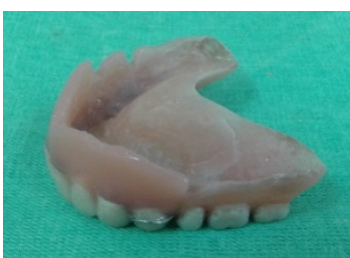

Fig. 10b
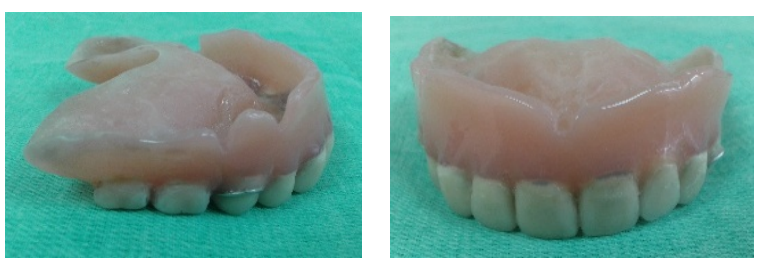

Fig. 10c

Fig. 10d

Fig. $10(a, b, c, d)$ - Completed denture - different perspectives

The second clinical stage was on the next day and the denture was placed into the mouth.

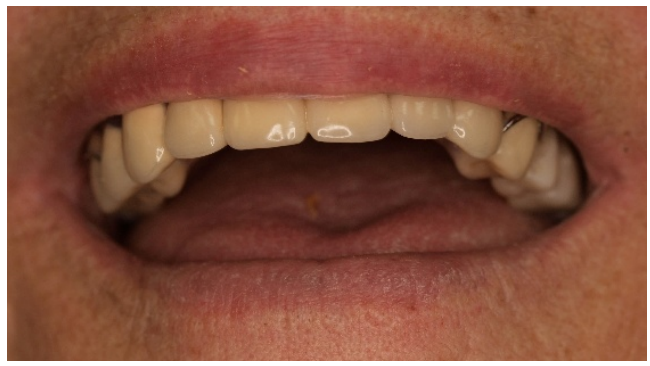

Fig. 11a

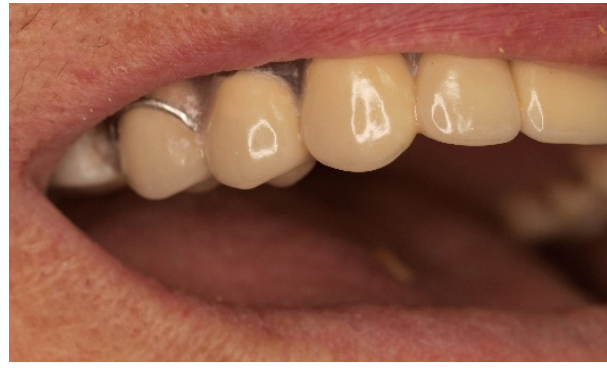

Fig.11b

Fig. $11(a, b)$ - The denture into the patient's mouth

\section{Discussion}

The advantages of the immediate dentures are indisputable. They have a prophylactic and psychological effect (2). The patient receives denture construction immediately after the teeth extraction, and it eliminates the waiting for the complete healing period of the wounds to occur and the shaping of the denture field (8).

The conventional or transitional immediate dentures make the treatment more expensive, but the patient easily makes the decision to extract his teeth after knowing the existence of these dentures.

These denture constructions result in a final denture of higher quality, they allow the surgical treatment to occur in one visit or according to medical indications, the latter to occur in several appointments (while planning overdenture immediate denture), allow duplicating of the shape and the position of the natural teeth and provide a spare denture during and after the fabricating of the definitive denture construction (4, $12,13,14)$. They do not change the appearance of the patient, the muscular tone and the size of the tongue (2). The immediate denture is used as a bandage, the extraction wound is covered with epithelium tissue faster and eliminates the pain (8). The jaw relation is preserved. Occlusal-articulation contacts, the chewing and speaking function are easily resumed because the patient is toothless only for a short period of time (2). 
The disadvantages of the immediate denture treatment are connected to the necessity of multiple relining of the denture constructions as a result of atrophy and resorptive processes in the area of the extracted teeth (8).

\section{Conclusion}

The functional, aesthetic and psycho-preventional value of the immediate treatment justifies its significance. By the fabrication of the immediate transitional denture, we improved the comfort of the patient regarding the aesthetics and function and we increased the quality of her life.

\section{References}

1. Caputi S. et al.: Immediate denture fabrication: a clinical report. Ann Stomatol (Roma). 2013 Jul-Sep, 4(3-4): 273-277.

2. Filchev A.: Clinic of Prosthetic dentistry. Mind Print, Sofia, 2014:276-279. (in Bulgarian)

3. Smith DE.: Interim dentures and treatment dentures. Dent Clin North Am. 1984 Apr;28(2):253271.

4. Khan Z, Haeberle CB.: One appointment construction of an immediate transitional complete denture using visible light-cured resin. J Prosthet Dent. 1992;68(3):500-502.

5. Woloch MM. Non traumatic immediate complete denture placement: a clinical report. J Prosthet Dent. 1998;80:391-3.

6. Phoenix RD, Fleigel JD.: Cast modification for immediate complete dentures: Traditional and contemporary considerations with an introduction of spatial modelling. J Prosthet Dent. Dec 2008, 100(5):399-405.

7. Seals RR, Kuebker WA, Stewart KI.: Immediate complete dentures. Dent Clin North Am. 1996,40(1):151-167.

8. Popov N.: Clinic of Prosthetic dentistry. Sofia, 1992:228, 256-257. (in Bulgarian)

9. McEntee Michael I., PhD, LDS(I), Dip Prosth, FRCD (C). The Complete Denture, A Clinical Pathway. Quintessence Publishing Co, Inc, 1999:89-95.

10 Jivanescu A. et al.: Immediate Complete Denture: A Case Report. TMJ 2003, 53(3-4): 293296.

11. Kraljevie S. et al.: Immediate Complete Denture. Acta Stomatol Croat. 2001, 35(2):281-285.

12. Gooya A. et al.: Fabricating an interim immediate partial denture in one appointment (modified jiffy denture). A clinical report. J Prosthodont. Jun 2013, 22(4):330-333. 
13 Memari Y., Gooya A.: Single - Appointment Fabrication of Interim Immediate Denture: A Clinical Report. J Dent School 2013; 31(2):125-130.

14. Tuncel I, Celik G.: A Clinical Pathway for Fabrication of Immediate Complete Dentures. Int J Prosthodont Restor Dent. 2015, 5(2):60-62.

\section{Corresponding author:}

Assistant Professor Mariana Yankova;

Department of Prosthetic Dentistry, Faculty of Dental Medicine, Medical University - Sofia; Georgi Sofiyski blvd., 1431 Sofia, Bulgaria;

Telephone number: +359 888440 823; E-mail address: m.jankova@abv.bg 